\title{
HEALING OF SUB-CRITICAL FEMORAL OSTEOTOMIES IN MICE IS UNAFFECTED BY TACROLIMUS AND DELETION OF RECOMBINATION ACTIVATING GENE 1
}

\author{
T-Y. Liu ${ }^{1}$, M. Bartnikowski², A.C. Wu ${ }^{3}$, M. Veitch ${ }^{1}$, K.A. Sokolowski', S.M. Millard ${ }^{3}$, A.R. Pettit ${ }^{3}$, V. Glatt ${ }^{5}$, \\ C.H. Evans ${ }^{6}$ and J.W. Wells ${ }^{1, *}$
}
${ }^{1}$ The University of Queensland Diamantina Institute, Faculty of Medicine, The University of Queensland, Woolloongabba, QLD 4102, Australia
${ }^{2}$ School of Dentistry, The University of Queensland, Herston, QLD 4006, Australia
${ }^{3}$ Mater Research Institute - The University of Queensland, Faculty of Medicine,
The University of Queensland, Woolloongabba, QLD 4102, Australia
${ }^{4}$ Translational Research Institute Preclinical Imaging Facility, Translational Research Institute,
Woolloongabba, QLD 4102, Australia
${ }^{5}$ Department of Orthopaedic Surgery, University of Texas Health Science Centre San Antonio, San Antonio, TX, USA
${ }^{6}$ Rehabilitation Medicine Research Centre, Mayo Clinic, Rochester, MI, USA

\begin{abstract}
Clinical management of delayed healing or non-union of long bone fractures and segmental defects poses a substantial orthopaedic challenge. There are suggestions in the literature that bone healing may be enhanced by inhibiting the activities of $\mathrm{T}$ and $\mathrm{B}$ lymphocytes, but this remains controversial. To examine this matter in more detail, sub-critical-sized segmental defects were created in the femora of mice and it was assessed whether there might be a benefit from the administration of a Food and Drug Administration (FDA)-approved drug that blocks $\mathrm{T}$ cell activation (tacrolimus). Defects were stabilised using an internal plate. In certain groups of animals, $1 \mathrm{mg} / \mathrm{kg}$ or $10 \mathrm{mg} / \mathrm{kg}$ tacrolimus was delivered locally to the defect site for 3 or $7 \mathrm{~d}$ using an implanted osmotic pump with a silicon catheter directing drug delivery into the defect area. Healing was monitored by weekly X-ray and assessed at 12 weeks by mechanical testing, $\mu \mathrm{CT}$ and histology. Radiographic and histological evaluations revealed that $100 \%$ of defects healed well regardless of tacrolimus dosage or duration. A comparison of healed C57BL/6 and Rag $1^{-/}$femora by $\mu \mathrm{CT}$ and ex vivo torsion testing showed no differences within mouse strains in terms of bone volume, tissue volume, bone volume/tissue volume ratio, shear modulus, torsional rigidity or torsional stiffness. These data failed to support an important role for tacrolimus in modulating the natural healing of segmental defects under those experimental conditions.
\end{abstract}

Keywords: Tacrolimus, FK506, bone healing, immunosuppression, local administration, mouse.

*Address for correspondence: J.W.Wells, The University of Queensland Diamantina Institute, 37 Kent Street, Woolloongabba, QLD 4102, Australia.

Email: j.wells3@uq.edu.au

Copyright policy: This article is distributed in accordance with Creative Commons Attribution Licence (http://creativecommons.org/licenses/by-sa/4.0/).

\begin{tabular}{|c|c|c|c|}
\hline BMD & bone mineral density & MSC & mesenchymal stem cell \\
\hline BMP-2 & bone morphogenetic protein-2 & NFAT & nuclear factor of activated $\mathrm{T}$ cell \\
\hline BV & bone volume & NOD & non-obese diabetic \\
\hline$C D$ & cluster of differentiation & PEEK & polyether ether ketone \\
\hline CXCL10 & $\mathrm{C}-\mathrm{X}-\mathrm{C}$ motif chemokine ligand 10 & PMMA & polymethyl methacrylate \\
\hline EDTA & ethylenediaminetetraacetic acid & pMOI & polar moment of inertia \\
\hline FDA & Food and Drug Administration & Rag1 & recombination activating gene 1 \\
\hline $\mathrm{H} \& \mathrm{E}$ & haematoxylin and eosin & Runx-2 & Runt-related transcription factor 2 \\
\hline IFN- $\gamma$ & interferon-gamma & SCID & severe combined immunodeficiency \\
\hline
\end{tabular}




$\begin{array}{ll}\text { SEM } & \text { standard deviation of the mean } \\ \text { Smad-7 } & \begin{array}{l}\text { Mothers against decapentaplegic } \\ \text { homolog } 7\end{array} \\ \text { TNF- } \alpha & \text { tumour necrosis factor-alpha } \\ \text { TV } & \text { total volume }\end{array}$

\section{Introduction}

The bone is one of the few human organs with the intrinsic ability to heal without scarring. Successful bone healing occurs as the result of a finely tuned sequence of consecutive processes, which begin with the early inflammatory phase. During this initial phase, damaged cells and tissues recruit an influx of immune cells such as macrophages and T cells, which release a plethora of cytokines to stimulate angiogenesis, enhance extracellular matrix synthesis and promote osteogenesis through the recruitment and differentiation of MSCs. These early events lead to the formation of a cartilaginous soft callus, which forms a hard callus following mineralisation, and subsequently undergoes remodelling to adapt the bone to the mechanical strain it encounters during loading. Thus, the immune system is intimately involved in the bone healing process, especially during the early inflammatory healing phase (Schmidt-Bleek et al., 2015).

Reinke et al. (2013) reported a negative role for $\mathrm{T}$ cells in early bone repair in humans. The authors examined the peripheral blood of patients with normal and delayed fracture healing and found a correlation between the enrichment of terminally differentiated effector memory CD8 T cells and delayed fracture healing. These memory T cells were shown to be strong producers of IFN- $\gamma$, evidenced by the fact that IFN- $\gamma$ secretion by these cells could not be suppressed by human bone marrow-derived MSCs in vitro. Through studies conducted using immune deficient mouse models, it has been established that in addition to CD8 T cells (Reinke et al., 2013; Toben et al., 2011), CD4 T cells (Liu et al., 2011) and $\gamma \delta \mathrm{T}$ cells (Colburn et al., 2009) also play a negative role in bone formation and fracture healing, with enhanced bone regeneration occurring when these $T$ cell subsets are absent or depleted. Divergent results have been reported using $\operatorname{Rag} 1^{-/}$mice, which are genetically deficient in T and B cells. Toben et al. (2011) found accelerated bone healing, while Nam et al. (2012) reported the opposite. Moreover, NOD/SCID mice which lack normal functioning macrophages, natural killer cells, dendritic cells and lymphocytes - show impaired bone healing (Rapp et al., 2016), while there appears to be little impact on bone healing in B-celldeficient $\mu \mathrm{MT}$ mice (Raggatt et al., 2013).

Tacrolimus is of interest in the context of bone healing. BMP-2 is a powerful inducer of new bone formation in rodent segmental bone defect models (Wulsten et al., 2011). In the clinic, it is used for promoting spinal fusions; however, the emerging clinical consensus is that it provides only incremental improvement in treating long bone fractures. Darcy et al. (2012) recently screened 5405 FDA-approved drugs, known bioactives and compounds with novel chemical structures for their capacity to augment BMP-2-mediated osteoblast commitment in a murine myoblast cell line. Of these, 18 compounds were identified to promote osteoblast commitment. Notably, 4 of these 18 compounds were immunosuppressive drugs and included the calcineurin inhibitor tacrolimus (FK506), which was described to increase levels of phospho-Smad 1/5/8 protein and the transcription of Runx-2, osterix and Smad-7 in osteoblast precursor cells, consistent with a role in promoting osteoblast differentiation. Tacrolimus enhances osteogenesis by binding to FK-binding protein 12 within cells, which stimulates intra-cellular signalling through the Smad pathway (Kugimiya et al., 2005).

Tacrolimus works by inhibiting the protein phosphatase calcineurin, which in T cells is required for the activation of NFAT, a transcription factor that drives the transcription of pro-inflammatory cytokines, including IL-2, TNF- $\alpha$ and IFN- $\gamma$ (Marsland and Griffiths, 2002). Therefore, tacrolimus essentially prevents the transcription of proinflammatory cytokines necessary to elicit an effective $\mathrm{T}$ cell response. Tacrolimus also inhibits TNF- $\alpha$, IL-12 and CXCL10 production by dendritic cells (Naranjo-Gomez et al., 2006; Tiefenthaler et al., 2004), potentially affecting fracture healing by altering the activation, polarisation and migration of immune cell populations more generally. The systemic delivery of tacrolimus does not enhance fracture healing in various rodent models (Heilmann et al., 2013; Holstein et al., 2008; Voggenreiter et al., 2005), yet it results in a significant decrease in CD8 T cell counts and a marked increase in bone formation in intramuscularly implanted demineralised bone matrix in rats (Voggenreiter et al., 2000).

In humans, tacrolimus has become the drug of choice following solid-organ transplantation (Jung et al., 2015). Following transplant surgery, patients are treated with a cocktail of immunosuppressive drugs that commonly include glucocorticoids (e.g. prednisone), inhibitors of nucleotide synthesis (e.g. mycophenolate mofetil) and tacrolimus, which patients take daily for their entire lives to prevent organ rejection. While some earlier studies have described an association between tacrolimus use and loss of bone mineral density (Monegal et al., 2001; Stempfle et al., 2002), the patients in these studies were also taking glucocorticoids, which are wellrecognised for their role in bone loss (Agarwal and Adachi, 2021). Because tacrolimus is rarely used in isolation in humans, the direct impact of tacrolimus on bone healing in patients remains uncertain.

Recently, Liu et al. (2015) have reported that the transient administration of tacrolimus and SEW2871 aids the healing of critical-sized femoral defects in rats following the implantation of sheep tissues modified with a recombinant adenovirus vector to 
Table 1. Experimental design. Mice were assigned to experimental groups as indicated. Saline or tacrolimus (two different concentrations) was released through an osmotic pump locally into the defect site. Some pumps released saline/tacrolimus over the first $3 \mathrm{~d}$ post-surgery, while others released tacrolimus over the first $7 \mathrm{~d}$ post-surgery. All animals were subjected to weekly X-rays and euthanised after 12 weeks. Healing of the defects was analysed in 6 mice/group by $\mu \mathrm{CT}$ and mechanical testing. The remainder were used for histology.

\begin{tabular}{|l|c|c|c|}
\hline Mouse strain & Defect treatment & Number of days & Number of mice \\
\hline C57BL $/ 6$ & Saline & 3 & 7 \\
\hline C57BL $/ 6$ & $1 \mathrm{mg} / \mathrm{kg}$ tacrolimus & 3 & 8 \\
\hline C57BL $/ 6$ & $10 \mathrm{mg} / \mathrm{kg}$ tacrolimus & 3 & 8 \\
\hline C57BL $/ 6$ & $1 \mathrm{mg} / \mathrm{kg}$ tacrolimus & 7 & 7 \\
\hline C57BL $/ 6$ & $10 \mathrm{mg} / \mathrm{kg}$ tacrolimus & 7 & 8 \\
\hline Rag $1^{-/-}$ & Saline & 3 & 7 \\
\hline Rag $1^{-/-}$ & $1 \mathrm{mg} / \mathrm{kg}$ tacrolimus & 3 & 8 \\
\hline Rag $1^{-/-}$ & $10 \mathrm{mg} / \mathrm{kg}$ tacrolimus & 3 & 8 \\
\hline Rag $1^{-/-}$ & $1 \mathrm{mg} / \mathrm{kg}$ tacrolimus & 7 & 7 \\
\hline Rag $1^{-/-}$ & $10 \mathrm{mg} / \mathrm{kg}$ tacrolimus & 7 & 8 \\
\hline
\end{tabular}

secrete BMP-2. The improved healing was associated with the suppression of cell-mediated and IgM and IgG antibody immune responses directed against sheep cells. However, whether tacrolimus played a direct role in healing independent of impacts on $\mathrm{T}$ cells and $\mathrm{B}$ cells was not assessed given the abundance of both immune cell populations in the host. To address this question further, the present study was based on a mouse model (Liu et al., 2013) that allowed examining the impact of tacrolimus on healing in immune-competent animals (C57BL/6), as well as in animals genetically deficient in T and B cells $\left(\right.$ Rag $\left.^{1^{--}}\right)$. Furthermore, given the paucity of literature concerning the direct influence of tacrolimus on the healing of segmental defects when used locally, the local delivery of tacrolimus into the defect area was examined.

\section{Materials and Methods}

\section{Study design}

A $1.5 \mathrm{~mm}$ sub-critical sized mid-femoral defect was created in the right hind limb of 38 male C57BL/6 (immune-competent) mice and 38 Rag1 $1^{-/}$(immunedeficient) mice following stabilisation with an internal, radiolucent PEEK MouseFix 6 plate (Inzana et al., 2014). Mice were randomly divided into 5 experimental groups (per strain), as detailed in Table 1. FK506 (tacrolimus; LC Labs, Woburn, MA, USA) was delivered locally and continuously to the defect through a polyethylene tube attached to a subcutaneously situated osmotic pump (Skoglund and Aspenberg, 2007). The osmotic pump released a volume of $0.5 \mu \mathrm{L} / \mathrm{h}$ into the defect area and the mice received an approximate local drug dose of 1 or $10 \mathrm{mg} / \mathrm{kg}$ body weight each day for 3 or $7 \mathrm{~d}$ post-surgery. Defects were monitored weekly using a closed cabin Faxitron MX 20 X-ray unit (Faxitron
Bioptics LLC, Tucson, AZ, USA). At 12 weeks, all animals were euthanised and excised femora were wrapped in gauze and stored at $-20^{\circ} \mathrm{C}$ for $\mu \mathrm{CT}$ and mechanical testing or at $4{ }^{\circ} \mathrm{C}$ for histology, to assess bone defect healing.

\section{Mice}

All animal procedures were approved by the University of Queensland Animal Ethics Committee, Approval Number 045/16. C57BL/6J and Rag1 $1^{-/-}$mice were purchased from the Animal Resources Facility Perth, Australia. Rag1 $1^{-/-}$mice are homozygous for the Rag1 $1^{\text {tm1Mom }}$ mutation and do not produce mature T or B cells (Mombaerts et al., 1992). All mice were housed under specific pathogen-free conditions at the Biological Research Facility, Translational Research Institute, Brisbane, Australia. Jung et al. (2018) confirmed that mice in this facility are fully immune-competent (unless genetically immunocompromised).

\section{Surgical procedure}

Animals were divided randomly into 10 experimental groups (Table 1). A $1.5 \mathrm{~mm}$ mid-femoral defect was created in the right hind limb of each mouse. Briefly, under sterile conditions, a $9 \mathrm{~mm}$ longitudinal incision was made on the lateral aspect of the thigh, creating a plane through the lateral intermuscular septum to expose the femur. Held by microsurgical tying forceps, an internal plate (MouseFix 6; RISystem AG, Davos, Switzerland) was placed on the anterior surface of the femur and gently clamped together with the femur. Six transcortical holes were drilled through the holes in the plate and screwed in place using titanium screws. A saw guide was used to create a $1.5 \mathrm{~mm}$ osteotomy at the femoral midshaft using a $0.22 \mathrm{~mm}$ sterile wire Gigli saw (RISystem AG). Then, bone debris was flushed from the defect region. A polyethylene tube was attached to an osmotic pump 
(\#1003D or \#1007D, Alzet Osmotic Pumps, Cupertino, CA, USA) containing saline \pm tacrolimus and the open end of the tube was fixed adjacent to the defect region by attachment to a suture tied around the plate between the proximal-most middle and outside pins. Then, muscle and skin were closed in layers with sterile sutures such that the osmotic pump was held subcutaneously between the muscle and the skin on the lower back. Autoclip wound clips were used to close the skin incision. Osmotic pumps remained in place for the duration of the experiment to reduce the risk of infection associated with a second surgery.

\section{Radiographic evaluation}

Bone healing was evaluated by radiography at weekly intervals using a closed cabin Faxitron ${ }^{\circledR}$ MX-20 X-ray unit (Faxitron Bioptics LLC, Tucson, AZ, USA). While under general anaesthesia, mice were placed in a ventral position and the hind limbs were laterally rotated to have a reproducible positioning.

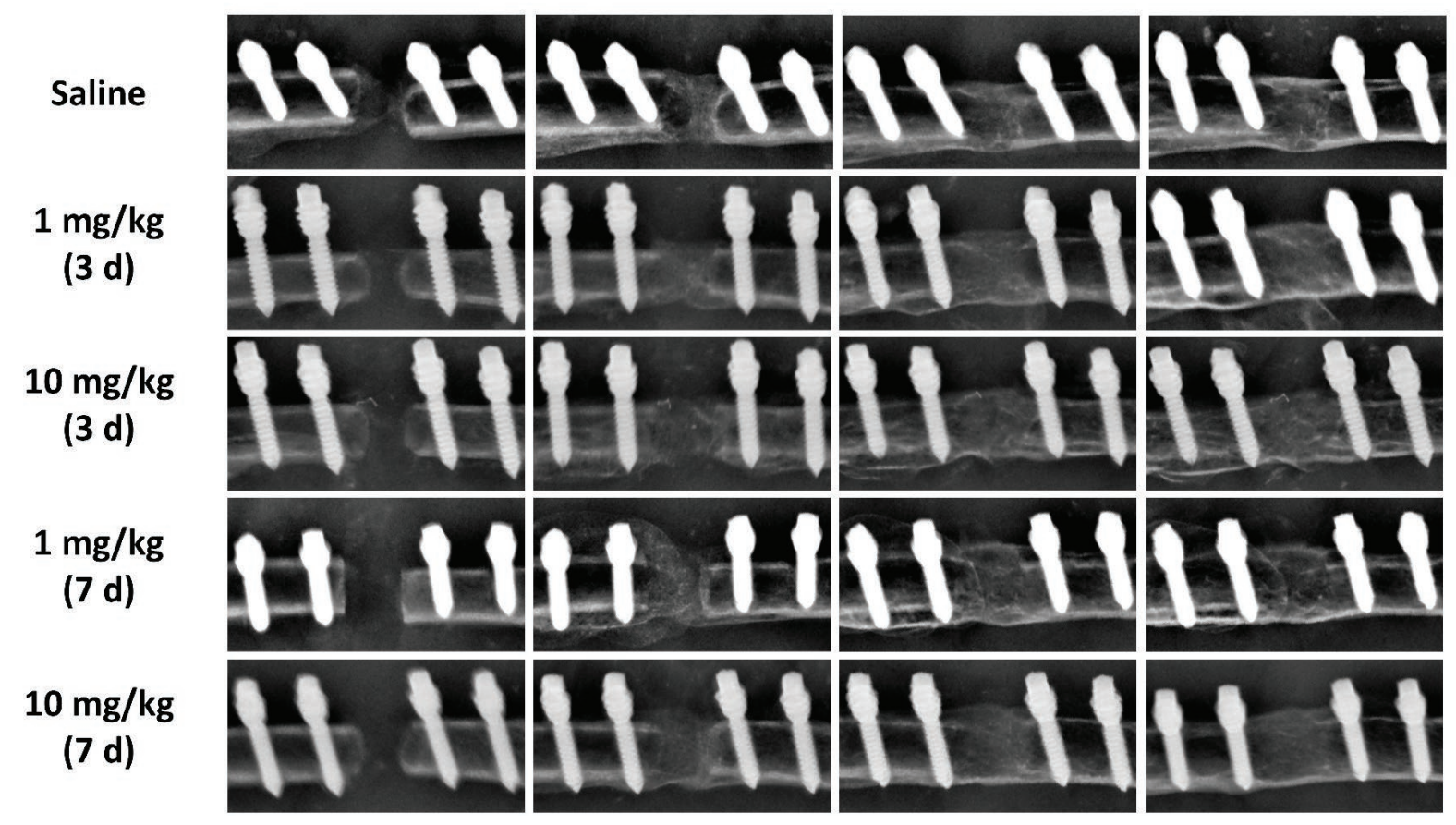

b

Week 1

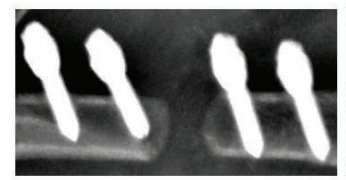

Saline

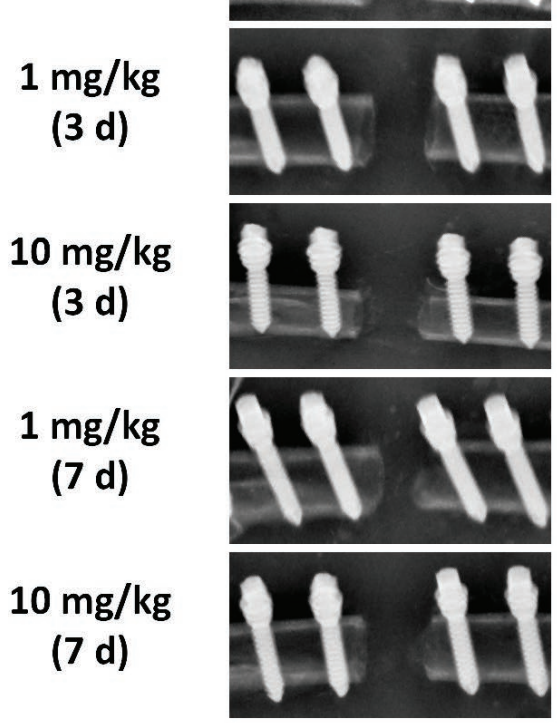

Week 3
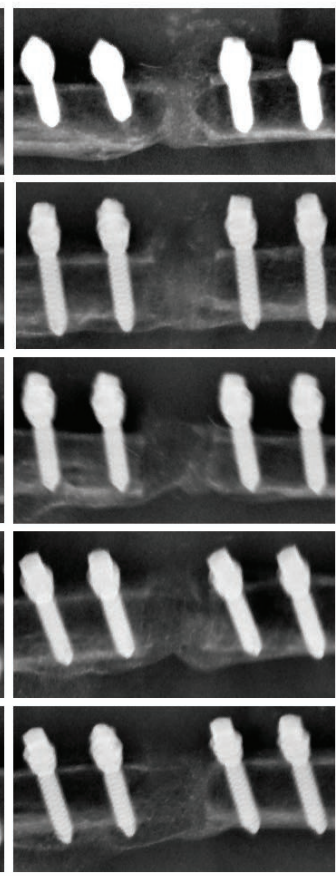

Week 6
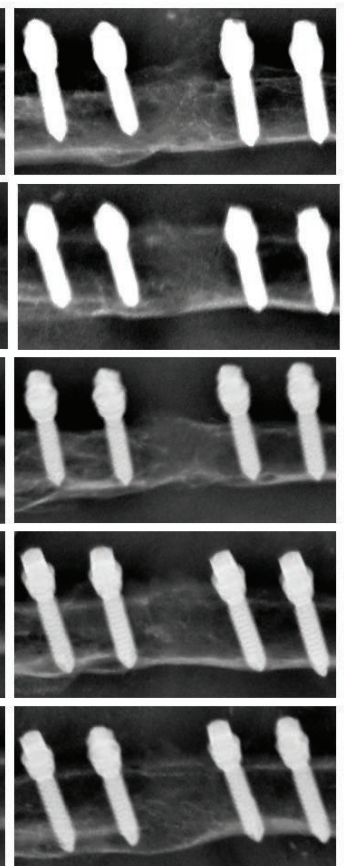

Week 12
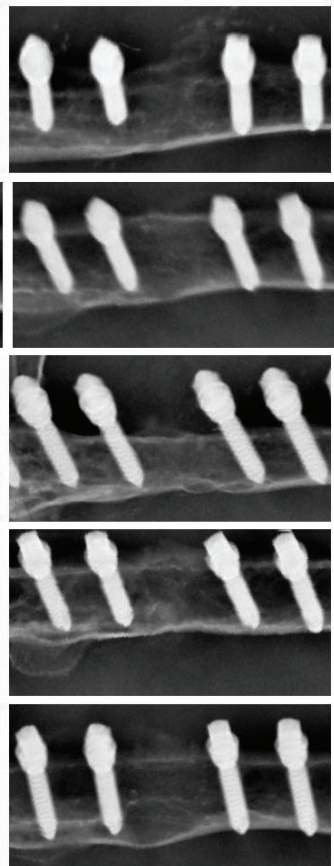

Fig. 1. Radiographs of femoral defects in mice at different time points after treatment with the indicated doses of tacrolimus for 3 or 7 d. (a) C57BL/6 mice. (b) Rag $1^{-/-}$mice. 
$\mu \mathrm{CT}$

Samples were scanned using a Skyscan $1272 \mu \mathrm{CT}$ instrument (Bruker) equipped with a microfocus X-ray tube with $\mathrm{a}<5 \mu \mathrm{m}$ spot size. All femora were scanned at isotropic voxel size of $10 \mu \mathrm{m}, 70 \mathrm{kV}$, $142 \mathrm{~mA}, 470 \mathrm{~ms}, 0.5 \mathrm{~mm}$ aluminium filter, along with rotation at $360^{\circ}$ with $0.8^{\circ}$ step increments. For each specimen, cross-sectional images were reconstructed using the NRecon software (version 1.7.3.1, Bruker). The area between the edges of the screw holes proximal and distal to the osteotomy site were used to define the volume of interest. The osteotomy site midpoint was used as a reference point, with 85 cross-sectional slices proximal and distal for analysis, yielding a total of 171 2-D slices. The TV of healed sub-critical defects or callus size $\left(\mathrm{mm}^{3}\right), \mathrm{BV}\left(\mathrm{mm}^{3}\right), \mathrm{BV} / \mathrm{TV}(\%), \mathrm{pMOI}\left(\mathrm{mm}^{4}\right)$ and BMD $\left(\mathrm{g} / \mathrm{cm}^{3}\right)$ were analysed.
Ex vivo mechanical testing

After 12 weeks of healing and after all non-invasive imaging was completed, 6 specimens from each experimental group were stored at $-20^{\circ} \mathrm{C}$ in salinesoaked gauze prior to mechanical testing. Before testing, each internal plate was removed and both ends of each femur were embedded in PMMA bone cement (Parapress ${ }^{\circledR}$ vario, Kulzer, South Bend, IN, USA) and tested to failure using a torsional testing adapter for an Instron MicroTester 5848 material testing system (Instron, Norwood, MA, USA) equipped with a $100 \mathrm{~N}$ load cell. A $1^{\circ} \mathrm{S}^{-1}$ strain rate was used and angular deformation and applied load data were acquired at $200 \mathrm{~Hz}$. Shear modulus (G; GPa), torsional rigidity $\left(w_{\mathrm{T}} ; \mathrm{Nm}^{2}\right)$ and torsional stiffness $(k ; \mathrm{Nm})$ were calculated to determine the torsional strength and stiffness of the healed subcritical defects.
C57BL/6

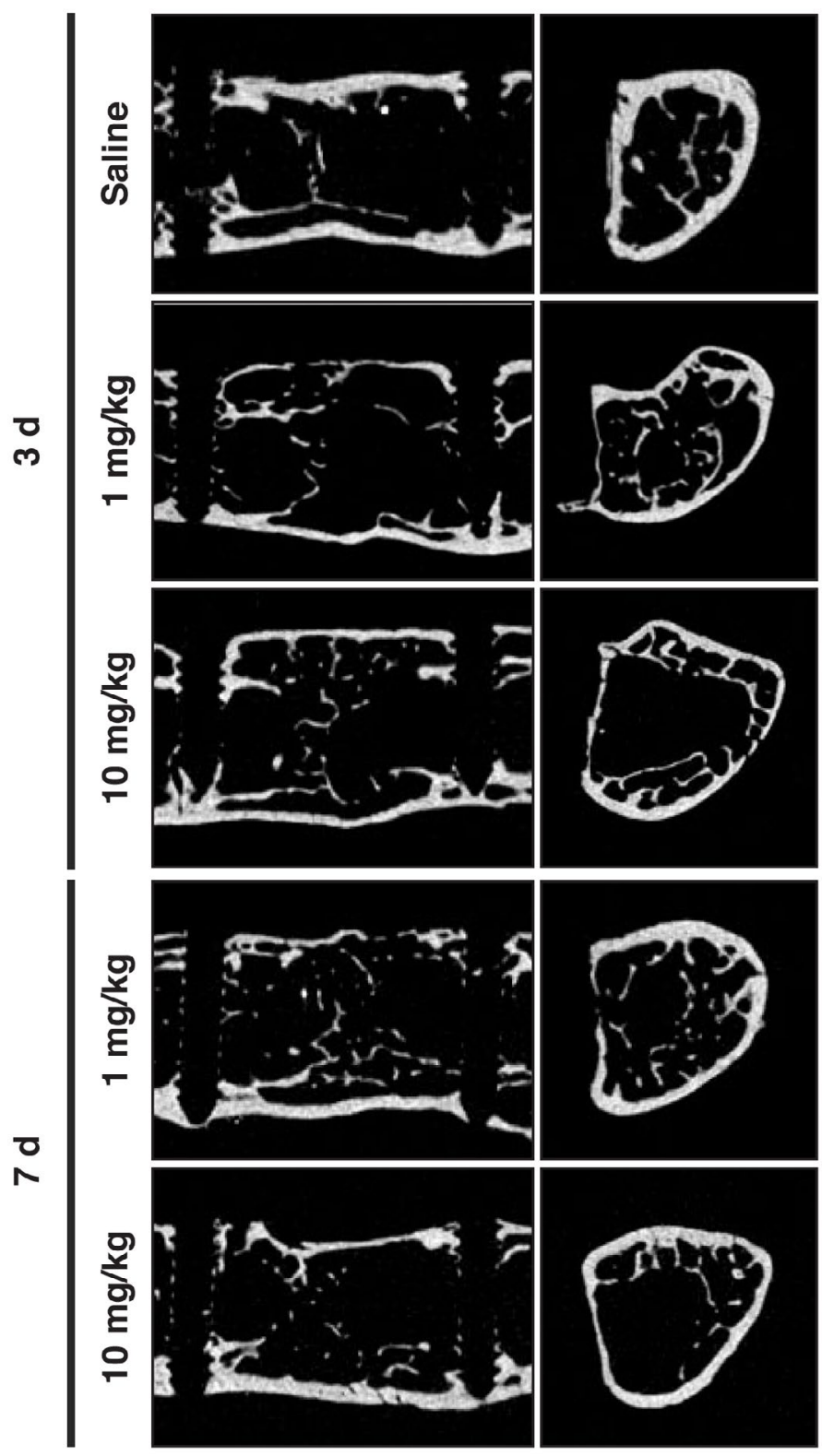

RAG1 -/-
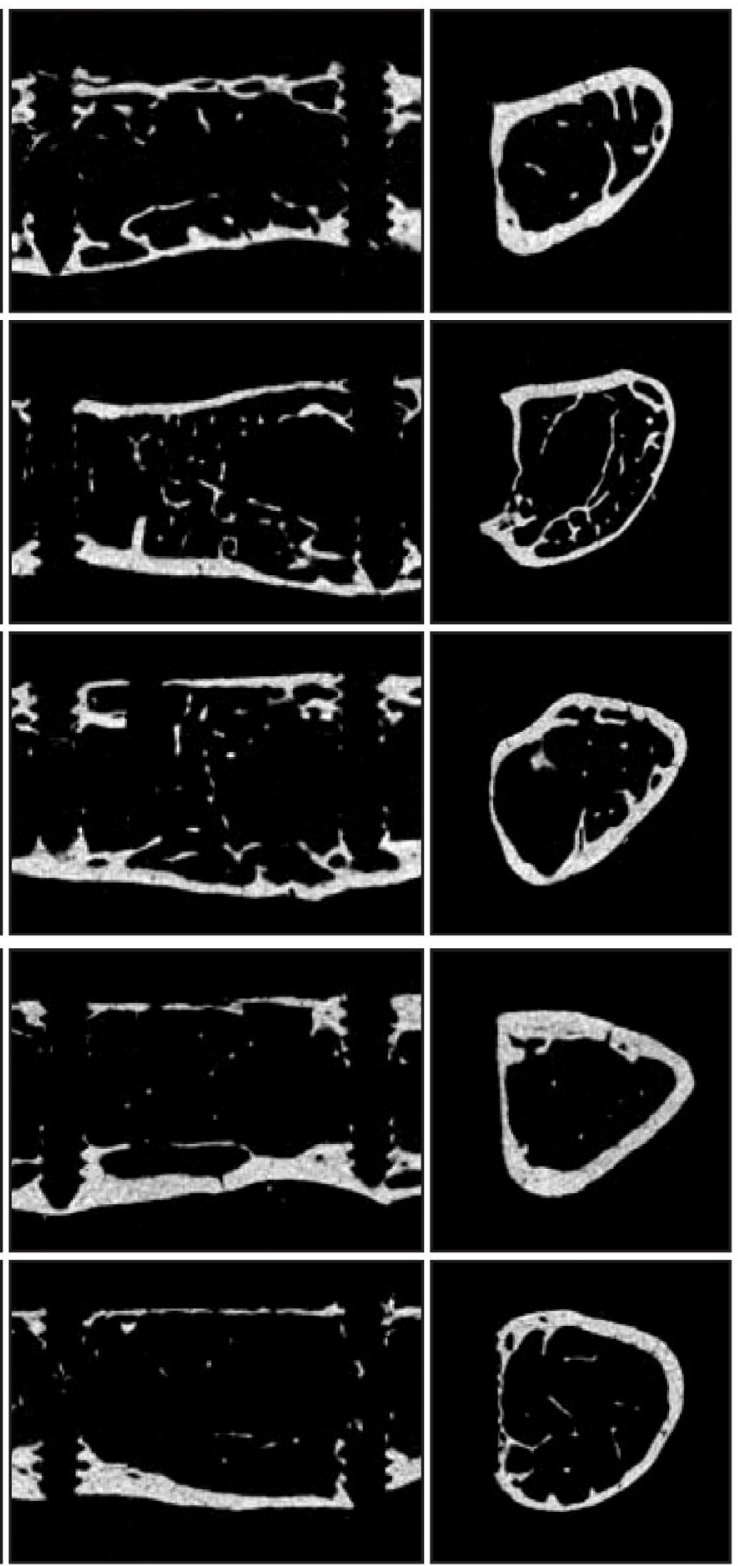

Fig. 2. Representative $\mu \mathrm{CT}$ images in the centre of healed defects at 12 weeks. Scale bar: $1 \mathrm{~mm}$. 


\section{Histology}

Right femora were harvested and fixed for $48 \mathrm{~h}$ at $4{ }^{\circ} \mathrm{C}$ in $4 \%$ ice-cold paraformaldehyde before decalcification using $20 \%$ EDTA in $0.1 \mathrm{~mol} / \mathrm{L}$ phosphate buffer (pH 7.4). After 4 weeks, samples were dehydrated in graded ethanol and embedded in paraffin-wax. Sections were stained using $\mathrm{H} \& \mathrm{E}$ by the QIMR Berghofer Histology Facility, Herston, Australia.

\section{Statistical analysis}

Statistical analysis was carried out using GraphPad Prism version 7.03 (GraphPad Software). Comparisons between multiple groups were performed using a one-way ANOVA with post-hoc Tukey's multiple comparisons test. A $p<0.05\left(^{*}\right)$ was considered statistically significant. Data are presented as mean \pm SEM.

\section{Results}

Bone healing in immune-competent and immunedeficient mice

To investigate the impact of local tacrolimus delivery on the healing of sub-critical sized mid- femoral defects in the presence or absence of $\mathrm{T}$ cells, immune-competent male C57BL/6 mice and immune-deficient male Rag1 $1^{-/}$mice were examined, as detailed in Table 1. Rag1 $1^{-/-}$mice are homozygous for a targeted mutation in Rag1 and are, therefore, unable to produce mature $\mathrm{T}$ or $\mathrm{B}$ cells. The inclusion of Rag $1^{-/-}$animals further allowed a determination as to whether tacrolimus might have a T cell- or B cellindependent effect on bone healing. The continuous local delivery of tacrolimus was investigated using two different doses delivered over 3 and $7 \mathrm{~d}$ via osmotic pumps. Longitudinal X-ray images showed early evidence of bridging in all groups by week 3 , with no noticeable differences in the healing outcomes at week 12 (Fig. 1).

The quantitative assessment by $\mu \mathrm{CT}$ at the experimental end point was mostly in agreement with the radiographic observations (Fig. 2,3). The only significant difference was observed in the BV/ TV measurement, which was lower in the $1 \mathrm{mg} /$ $\mathrm{kg}$ tacrolimus day $3 \mathrm{Rag}^{-/-}$group compared to the $10 \mathrm{mg} / \mathrm{kg}$ tacrolimus day 7 C57BL/6 group after 12 weeks of treatment (Fig. 3c). All tacrolimus treatment conditions resulted in marginally elevated pMOI over saline controls; however, none of the differences were significant (Fig. 3d).
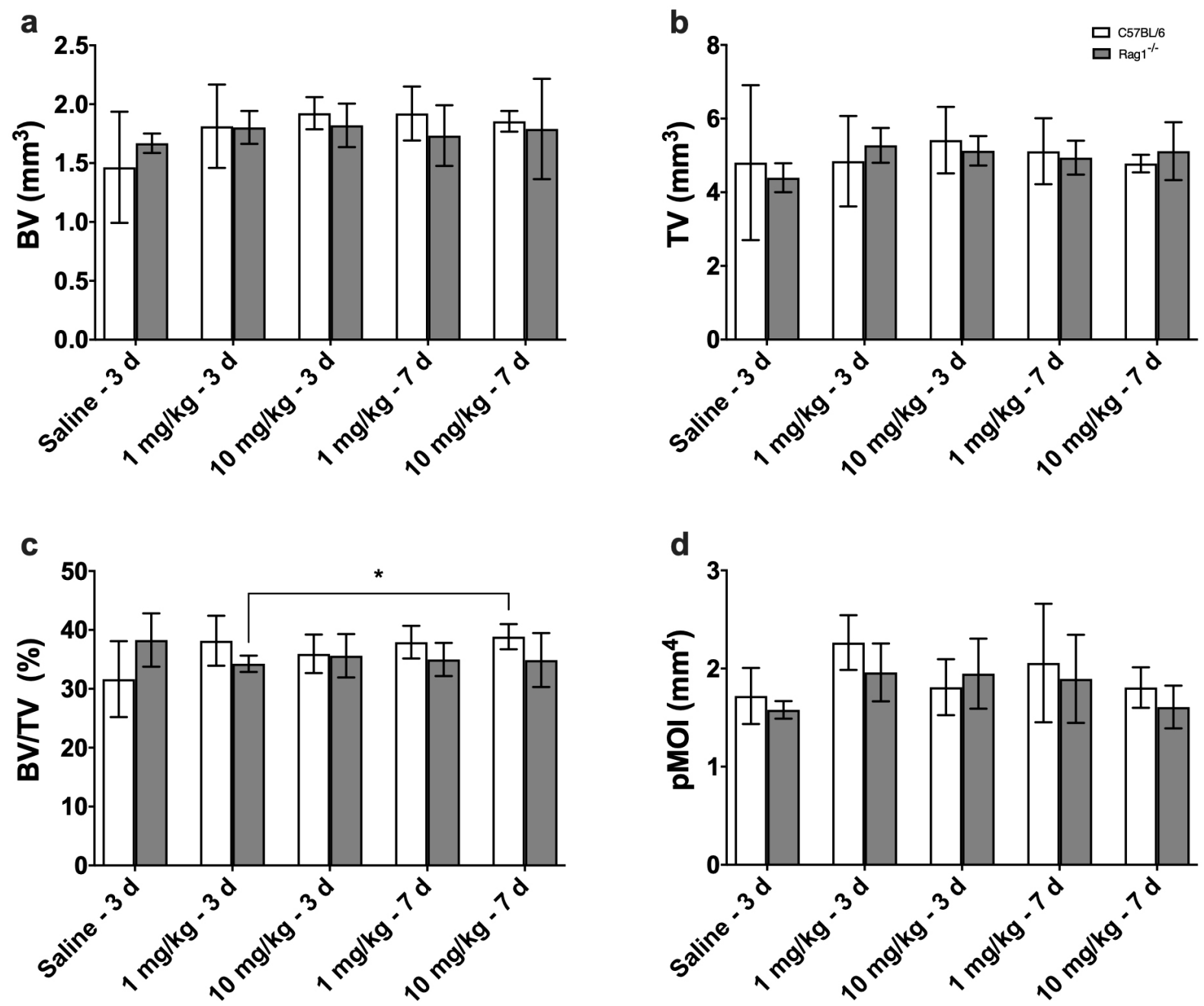

Fig. 3. Bone morphological and geometric values obtained from $\mu \mathrm{CT}$. (a) BV, (b) TV or callus size, (c) BV/ TV and (d) pMOI. 
Qualitative histological analysis of defect areas confirmed complete bridging in all defect groups at week 12 (Fig. 4), as was evidenced by an almost completely remodelled cortical circumference, very little trabeculation within the defect area as well as restoration of marrow. No cartilage was detected histologically in the defect area at this time point in any of the experimental groups (data not shown).

Mechanical properties of healed bones at 12 weeks Overall, limited differences were observed between C57BL/6 and Rag $1^{-/}$mouse strains, tacrolimus dosage and time points tested (Fig. 5). Shear modulus in the $10 \mathrm{mg} / \mathrm{kg}$ tacrolimus groups demonstrated the highest values in mice that received tacrolimus for $3 \mathrm{~d}$. However, mice that received tacrolimus for $7 \mathrm{~d}$ were among the ones with the lowest values (Fig. 5a). Moreover, a significant difference was also observed between C57BL/6 $10 \mathrm{mg} / \mathrm{kg}$ tacrolimus $3 \mathrm{~d}$ treatment and Rag1 ${ }^{-/-} 10 \mathrm{mg} / \mathrm{kg}$ tacrolimus $7 \mathrm{~d}$ treatment $(p=0.029)$. Rag $1^{-1-} 10 \mathrm{mg} / \mathrm{kg}$ tacrolimus $3 \mathrm{~d}$ treatment group, while showing higher values than the $7 \mathrm{~d}$ treatment group, failed to reach a statistically significant difference $(p=0.077)$. No significant

\section{C57BL/6}
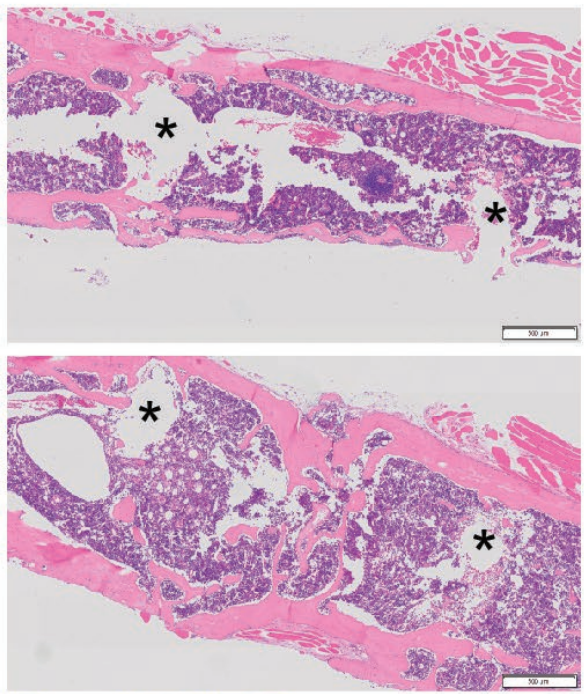

$1 \mathrm{mg} / \mathrm{kg}$

$(3 \mathrm{~d})$

Saline

$10 \mathrm{mg} / \mathrm{kg}$

(3d)
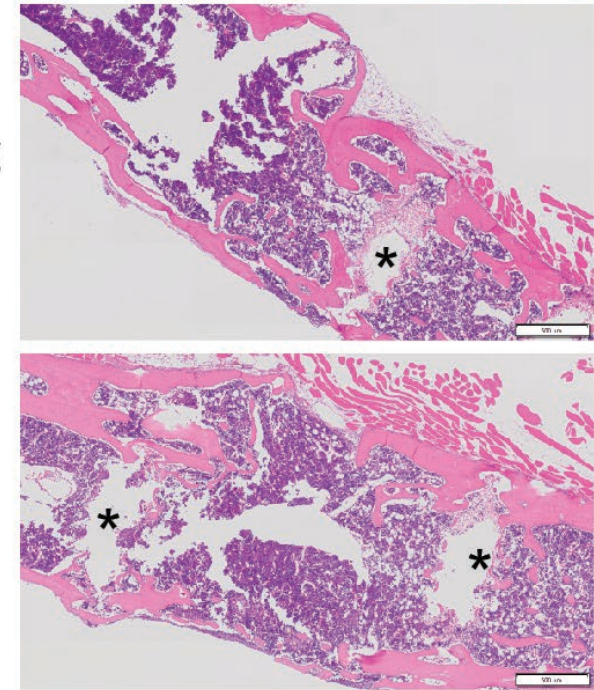

$1 \mathrm{mg} / \mathrm{kg}$

(7 d)

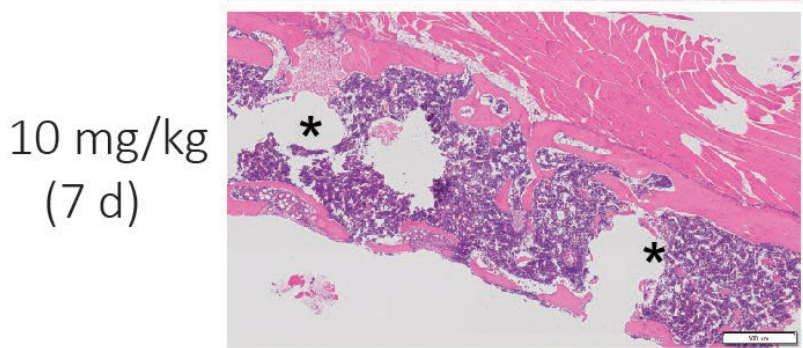

$\operatorname{Rag} 1 \%$
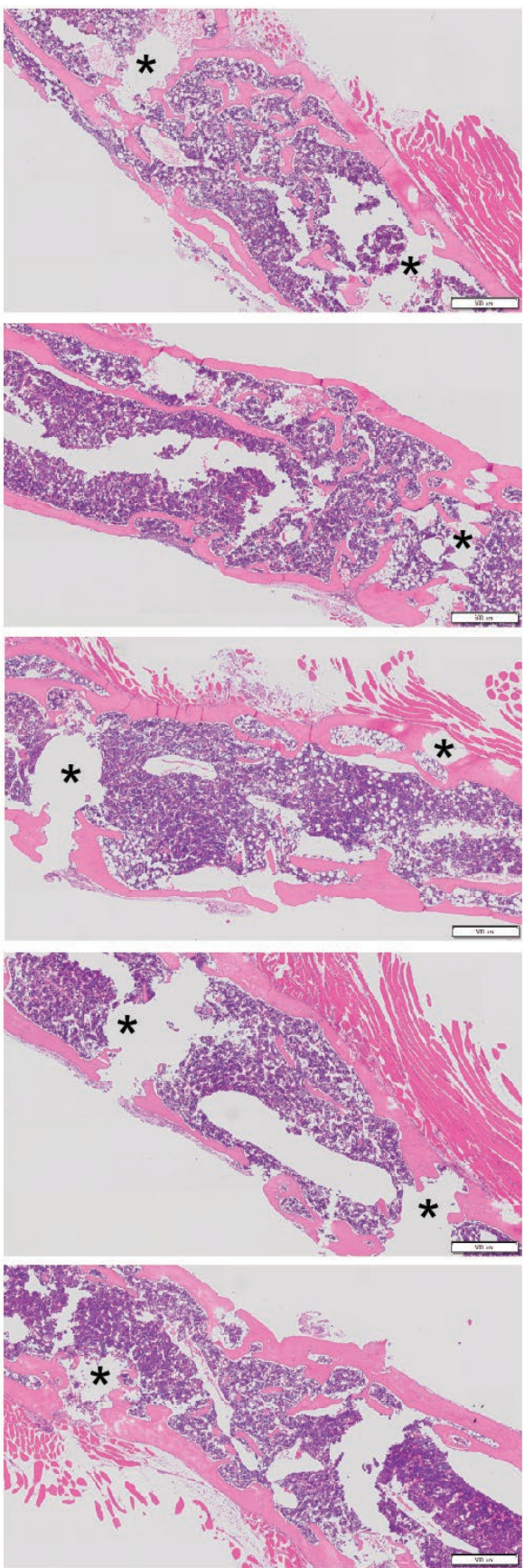

Fig. 4. Histological appearance of defects 12 weeks after the indicated tacrolimus treatments. Representative images of sections stained with H\&E in C57BL/6-(left-hand side) or Rag1/- mice (right-hand side). Asterisks in H\&E panels indicate the pin holes for the fixation plate. Scale bars: $500 \mu \mathrm{m}$. 
differences were observed between any other group and/or condition. Torsional rigidity showed some variation between the tested groups (Fig. 5b). For example, the Rag $1^{-/-} 10 \mathrm{mg} / \mathrm{kg}$ tacrolimus $7 \mathrm{~d}$ treatment group showed the lowest values and was significantly different when compared to the Rag1/$10 \mathrm{mg} / \mathrm{kg}$ tacrolimus $3 \mathrm{~d}$ treatment group $(p=0.029)$ and the C57BL/6 $1 \mathrm{mg} / \mathrm{kg}$ tacrolimus $7 \mathrm{~d}$ treatment group $(p=0.036)$. Furthermore, the $\operatorname{Rag} 1^{-/-} 10 \mathrm{mg} /$ $\mathrm{kg}$ tacrolimus $7 \mathrm{~d}$ treatment group reached near statistical significance as compared to C57BL/61 mg/ $\mathrm{kg}$ tacrolimus $3 \mathrm{~d}$ treatment group $(p=0.085)$ and the C57BL $/ 610 \mathrm{mg} / \mathrm{kg}$ tacrolimus $3 \mathrm{~d}$ treatment group $(p=0.061)$. Torsional stiffness (Fig. 5c) had a similar trend to torsional rigidity, with somewhat higher values observed in the $10 \mathrm{mg} / \mathrm{kg}$ tacrolimus group of both strains. In this case, a significant difference was only present between the Rag $1^{-/-} 10 \mathrm{mg} / \mathrm{kg}$ tacrolimus $3 \mathrm{~d}$ and $7 \mathrm{~d}$ treatment groups, with the $7 \mathrm{~d}$ treatment group again achieving the lowest values.

\section{Discussion}

Orthopaedists and traumatologists encounter several circumstances where bone healing is impaired, including when large segments of bone are lost as a result of disease, resection or trauma. The inability of critical-sized defects to heal represents a major clinical problem. Schmidt-Bleek et al. (2014; 2012) hypothesised that the regenerative bone healing process is dependent on a balanced immune reaction during the early inflammatory phase that, if disturbed, jeopardises a successful healing outcome. They demonstrated that impaired/delayed healing induced through mechanical factors is associated with prolonged inflammatory signals (Schmidt-Bleek et al., 2012) and prolonged pro-inflammatory cytokine secretion (Schmidt-Bleek et al., 2014). Furthermore, a significantly higher $\mathrm{T}$ cell abundance in the bone marrow next to the osteotomy gap is associated with impaired/delayed healing defects (Schmidt-Bleek et al., 2012). T cells are a rich source of the proinflammatory cytokines IFN- $\gamma$ and TNF- $\alpha$ (Wells et al., $2009 ; 2007)$. IFN- $\gamma$ is thought to inhibit the osteogenic differentiation of MSCs and, when present alongside TNF- $\alpha$, to direct MSCs to undergo apoptosis (Shi et al., 2012). Indeed, the combined neutralisation of IFN- $\gamma$ and TNF- $\alpha$ by antibody therapy allows for the generation of ectopic bone following the subcutaneous injection of bone marrow-derived MSCs into otherwise immune competent mice (Liu et al., 2011). Therefore, prolonged inflammation during the early inflammatory healing phase, is inhibitory for bone repair and, consequently, immunomodulatory approaches for enhanced bone tissue regeneration are being considered as future treatment options (Mountziaris and Mikos, 2008).

In particular, the healing response in Rag $1^{-1-}$ mice, which lack $\mathrm{T}$ cells, is intriguing given that the successful bone-healing cascade is thought to be initiated by an acute inflammatory response following the release of inflammatory cytokines, and T cells are known to be a rich source of these cytokines. However, it should be noted that inflammatory cytokines can also be secreted by innate immune cells and Rag $1^{-/-}$mice retain a full complement of innate immune cell populations. Thus, it is highly significant that tacrolimus did not show a major effect on bone healing in the present model. There are two previous reports concerning bone healing in Rag1 $1^{-/}$ mice, one of which reports impaired healing (Nam et al., 2012) and the other enhanced healing (Toben et al., 2011). These discordant results may reflect the nature of the defects studied. Nam et al. (2012) used a tibial osteotomy stabilised by an intramedullary pin, Tobin et al. (2011) used an unfixed closed femoral fracture. In the present study, a sub-critical sized femoral segmental defect stabilised with a plate was used. It is entirely possible that the nature of the osseous lesion and its fixation determines any role of lymphocytes or other immune cells in the healing process, especially as the mechanical environment has a major effect on inflammation and healing.

Data also demonstrated that tacrolimus had little effect on bone healing in either immunocompetent C57BL/6 or immunodeficient Rag1 $1^{-/-}$mice. This agrees with a recent publication by De la Vega et al. (2020) showing that tacrolimus does not influence the healing of critical sized femoral defects in rats receiving BMP-2. The lack of effect of tacrolimus on bone healing in Rag1 $1^{-/-}$mice suggests that its ability to promote osteogenesis through enhanced Smad signalling is not operative in the present model.

There is currently much interest in the possibility of enhancing bone healing clinically by
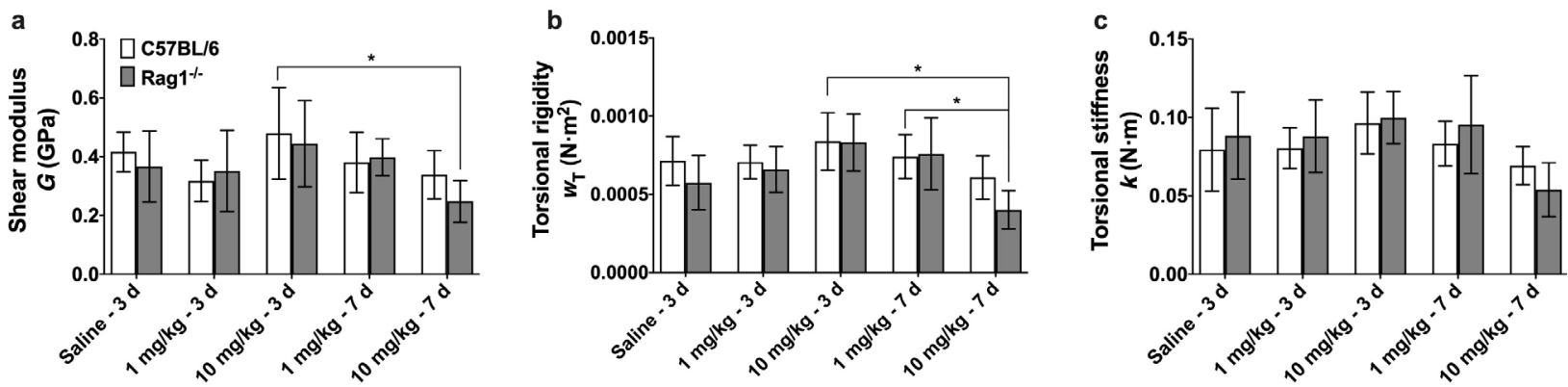

Fig. 5. Parameters calculated from ex vivo torsional testing. (a) Shear modulus, (b) torsional rigidity, (c) torsional stiffness. 
immunomodulation. Data described and discussed in the present study caution that any beneficial effect may be context dependent and clinical translation needs to proceed cautiously.

\section{Acknowledgements}

This work (project no. S-16-36W) was supported by the AO Foundation, Davos, Switzerland and the research was carried out at the Translational Research Institute (TRI), Woolloongabba, QLD 4102, Australia. The TRI is supported by a grant from the Australian Government. SMM, ACW and ARP are supported by Mater Foundation. The authors thank the TRI Preclinical Imaging Facility for excellent imaging and analytical support.

\section{References}

Agarwal A, Adachi JD (2021) Therapies for preventing bone loss with glucocorticoid treatment. Curr Osteoporos Rep 19: 34-39.

Colburn NT, Zaal KJ, Wang F, Tuan RS (2009) A role for gamma/delta $\mathrm{T}$ cells in a mouse model of fracture healing. Arthritis Rheum 60: 1694-1703.

Darcy A, Meltzer M, Miller J, Lee S, Chappell S, Ver Donck K, Montano M (2012) A novel library screen identifies immunosuppressors that promote osteoblast differentiation. Bone 50: 1294-1303.

De la Vega RE, Coenen MJ, Muller SA, Nagelli CV, Quirk NP, Lopez de Padilla C, Evans CH (2020) Effects of FK506 on the healing of diaphyseal, critical size defects in the rat femur. Eur Cell Mater 40: 160171.

Heilmann A, Schinke T, Bindl R, Wehner T, Rapp A, Haffner-Luntzer M, Liedert A, Amling M, Ignatius A (2013) Systemic treatment with the sphingosine-1phosphate analog FTY720 does not improve fracture healing in mice. J Orthop Res 31: 1845-1850.

Holstein JH, Klein M, Garcia P, Histing T, Culemann U, Pizanis A, Laschke MW, Scheuer C, Meier C, Schorr H, Pohlemann T, Menger MD (2008) Rapamycin affects early fracture healing in mice. $\mathrm{Br}$ J Pharmacol 154: 1055-1062.

Inzana JA, Olvera D, Fuller SM, Kelly JP, Graeve OA, Schwarz EM, Kates SL, Awad HA (2014) 3D printing of composite calcium phosphate and collagen scaffolds for bone regeneration. Biomaterials 35: 4026-4034.

Jung JW, Overgaard NH, Burke MT, Isbel N, Frazer IH, Simpson F, Wells JW (2015) Does the nature of residual immune function explain the differential risk of non-melanoma skin cancer development in immunosuppressed organ transplant recipients? Int J Cancer 138: 281-292.

Jung JW, Veitch M, Bridge JA, Overgaard NH, Cruz JL, Linedale R, Franklin ME, Saunders NA, Simpson F, Frazer IH, Steptoe RJ, Wells JW (2018) Clinically-relevant rapamycin treatment regimens enhance CD8(+) effector memory T cell function in the skin and allow their infiltration into cutaneous squamous cell carcinoma. Oncoimmunology 7: e1479627. DOI: 10.1080/2162402X.2018.1479627.

Kugimiya F, Yano F, Ohba S, Igawa K, Nakamura K, Kawaguchi H, Chung UI (2005) Mechanism of osteogenic induction by FK506 via BMP/Smad pathways. Biochem Biophys Res Commun 338: 872879.

Liu F, Ferreira E, Porter RM, Glatt V, Schinhan M, Shen Z, Randolph MA, Kirker-Head CA, Wehling C, Vrahas MS, Evans CH, Wells JW (2015) Rapid and reliable healing of critical size bone defects with genetically modified sheep muscle. Eur Cell Mater 30: 118-130.

Liu K, Li D, Huang X, Lv K, Ongodia D, Zhu L, Zhou L, Li Z (2013) A murine femoral segmental defect model for bone tissue engineering using a novel rigid internal fixation system. J Surg Res 183: 493-502.

Liu Y, Wang L, Kikuiri T, Akiyama K, Chen C, Xu X, Yang R, Chen W, Wang S, Shi S (2011) Mesenchymal stem cell-based tissue regeneration is governed by recipient T lymphocytes via IFN-gamma and TNF-alpha. Nat Med 17: 1594-1601.

Marsland AM, Griffiths CE (2002) The macrolide immunosuppressants in dermatology: mechanisms of action. Eur J Dermatol 12: 618-622.

Mombaerts P, Iacomini J, Johnson RS, Herrup K, Tonegawa S, Papaioannou VE (1992) RAG-1-deficient mice have no mature B and T lymphocytes. Cell 68: 869-877.

Monegal A, Navasa M, Guanabens N, Peris P, Pons F, Martinez de Osaba MJ, Rimola A, Rodes J, Munoz-Gomez J (2001) Bone mass and mineral metabolism in liver transplant patients treated with FK506 or cyclosporine A. Calcif Tissue Int 68: 83-86.

Mountziaris PM, Mikos AG (2008) Modulation of the inflammatory response for enhanced bone tissue regeneration. Tissue Eng Part B Rev 14: 179-186.

Nam D, Mau E, Wang Y, Wright D, Silkstone D, Whetstone H, Whyne C, Alman B (2012) T-lymphocytes enable osteoblast maturation via IL17F during the early phase of fracture repair. PLoS One 7: e40044. DOI: 10.1371/journal.pone.0040044.

Naranjo-Gomez M, Climent N, Cos J, Oliva H, Bofill M, Gatell JM, Gallart T, Pujol-Borrell R, Borras FE (2006) Tacrolimus treatment of plasmacytoid dendritic cells inhibits dinucleotide (CpG-)-induced tumour necrosis factor-alpha secretion. Immunology 119: $488-498$.

Raggatt LJ, Alexander KA, Kaur S, Wu AC, MacDonald KP, Pettit AR (2013) Absence of B cells does not compromise intramembranous bone formation during healing in a tibial injury model. Am J Pathol 182: 1501-1508.

Rapp AE, Bindl R, Recknagel S, Erbacher A, Muller I, Schrezenmeier H, Ehrnthaller C, Gebhard F, Ignatius A (2016) Fracture healing is delayed in immunodeficient NOD/scid-IL2R $\gamma$ cnull mice. PLoS One 11: e0147465. DOI: 10.1371/journal.pone.0147465. 
Reinke S, Geissler S, Taylor WR, Schmidt-Bleek K, Juelke K, Schwachmeyer V, Dahne M, Hartwig T, Akyuz L, Meisel C, Unterwalder N, Singh NB, Reinke P, Haas NP, Volk HD, Duda GN (2013) Terminally differentiated CD8(+) T cells negatively affect bone regeneration in humans. Sci Transl Med 5: 177ra136. DOI: 10.1126/scitranslmed.3004754.

Schmidt-Bleek K, Kwee BJ, Mooney DJ, Duda GN (2015) Boon and bane of inflammation in bone tissue regeneration and its link with angiogenesis. Tissue Eng Part B Rev 21: 354-364.

Schmidt-Bleek K, Schell H, Lienau J, Schulz N, Hoff P, Pfaff M, Schmidt G, Martin C, Perka C, Buttgereit F, Volk HD, Duda G (2014) Initial immune reaction and angiogenesis in bone healing. J Tissue Eng Regen Med 8: 120-130.

Schmidt-Bleek K, Schell H, Schulz N, Hoff P, Perka C, Buttgereit F, Volk HD, Lienau J, Duda GN (2012) Inflammatory phase of bone healing initiates the regenerative healing cascade. Cell Tissue Res 347: 567-573.

Shi Y, Wei L, Wang Y, Ren G (2012) Stem cells deployed for bone repair hijacked by $\mathrm{T}$ cells. Cell Stem Cell 10: 6-8.

Skoglund B, Aspenberg P (2007) Locally applied Simvastatin improves fracture healing in mice. BMC Musculoskelet Disord 8: 98. DOI: 10.1186/1471-24748-98.

Stempfle HU, Werner C, Siebert U, Assum T, Wehr U, Rambeck WA, Meiser B, Theisen K, Gartner R (2002) The role of tacrolimus (FK506)based immunosuppression on bone mineral density and bone turnover after cardiac transplantation: a prospective, longitudinal, randomized, double-blind trial with calcitriol. Transplantation 73: 547-552.

Tiefenthaler M, Hofer S, Ebner S, Ivarsson L, Neyer S, Herold M, Mayer G, Fritsch P, Heufler C (2004) In vitro treatment of dendritic cells with tacrolimus: impaired T-cell activation and IP-10 expression. Nephrol Dial Transplant 19: 553-560.

Toben D, Schroeder I, El Khassawna T, Mehta M, Hoffmann JE, Frisch JT, Schell H, Lienau J, Serra A, Radbruch A, Duda GN (2011) Fracture healing is accelerated in the absence of the adaptive immune system. J Bone Miner Res 26: 113-124.

Voggenreiter G, Assenmacher S, Kreuzfelder E, Wolf M, Kim MR, Nast-Kolb D, Schade FU (2000) Immunosuppression with FK506 increases bone induction in demineralized isogeneic and xenogeneic bone matrix in the rat. J Bone Miner Res 15: 1825-1834.

Voggenreiter G, Siozos P, Hunkemoller E, Heute S, Schwarz M, Obertacke U (2005) Immunosuppression with FK506 has no influence on fracture healing in the rat. Bone 37: 227-233.

Wells JW, Choy K, Lloyd CM, Noble A (2009) Suppression of allergic airway inflammation and IgE responses by a class I restricted allergen peptide vaccine. Mucosal Immunol 2: 54-62.

Wells JW, Cowled CJ, Giorgini A, Kemeny DM, Noble A (2007) Regulation of allergic airway inflammation by class I-restricted allergen presentation and CD8 T-cell infiltration. J Allergy Clin Immunol 119: 226-234.

Wulsten D, Glatt V, Ellinghaus A, Schmidt-Bleek K, Petersen A, Schell H, Lienau J, Sebald W, Ploger F, Seemann P, Duda GN (2011) Time kinetics of bone defect healing in response to BMP-2 and GDF-5 characterised by in vivo biomechanics. Eur Cell Mater 21: 177-192.

\section{Discussion with Reviewers}

Katharina Schmidt-Bleek: How do you evaluate the immune reaction, which you wanted to improve by applying tacrolimus, within the animals?

Authors: The aim of the study was to assess the impact of tacrolimus on healing. The immune function was not specifically examined. If a major effect of tacrolimus had been found, it would have made sense to go back and study its immunological effects.

Katharina Schmidt-Bleek: How do you explain the differences in healing outcome in the Rag $1^{-/-}$animals treated with tacrolimus?

Authors: Although the most studied effect of Tacrolimus is T cell suppression, it affects cell types other than lymphocytes, including keratinocytes, dendritic cells and mesenchymal stromal cells. Thus, there are numerous alternative cellular targets for tacrolimus in $\mathrm{Rag}^{-/-}$animals.

Katharina Schmidt-Bleek: Why did you choose to analyse the 12 weeks healing time point when you were addressing the inflammatory healing phase within your experimental set up?

Authors: An analysis of the early inflammatory phase would have been logical if we had found an obvious difference in healing, which we did not.

Daniel Clark: Based on our understanding of the temporal regulation of the innate and adaptive immune cells during fracture healing, do you think your study design may influence fracture healing at earlier time points that were not evaluated in the study?

Authors: It is entirely possible that there may have been impacts at earlier time points yet to be described; however, we did not see an impact on healing outcomes overall in this model. If tacrolimus is to be used to enhance bone healing, it would need to be administered locally and, therefore, an important follow-up study could be to fully characterise the impact that local tacrolimus delivery has on local immune cell populations and their function.

Editor's note: The Guest Editor responsible for this paper was Anita Ignatius. 